\title{
Adult coeliac disease
}

\author{
Andrew D Hopper, ${ }^{1}$ Marios Hadjivassiliou, ${ }^{2}$ Sohail Butt, ${ }^{3}$ David S Sanders ${ }^{1}$
}

${ }^{1}$ Department of Gastroenterology, Royal Hallamshire Hospital, Sheffield S10 2JF

${ }^{2}$ Department of Neurology, Royal Hallamshire Hospital

${ }^{3}$ Studholme Medical Centre, Ashford TW15 2TU

Correspondence to: A D Hopper, Room P39, P Floor,

Gastroenterology and Liver Unit, Royal Hallamshire Hospital,

Sheffield S10 2JF

andydhopper@aol.com

BMJ 2007;335:558-62 doi:10.1136/bmi.39316.442338.AD
The prevalence of coeliac disease is $0.5-1 \%$ in international population studies. The delay in diagnosis is reported to range from 4.5 years to 9.0 years. ${ }^{12}$ Patients may present on numerous occasions to both primary and secondary care without coeliac disease being considered. ${ }^{3}$ Currently, for every adult patient in whom the disease is diagnosed, eight cases are estimated to go undetected. ${ }^{4}$

\section{What is coeliac disease and why is it more common now?}

Coeliac disease (or gluten sensitive enteropathy) is defined as a state of heightened immunological responsiveness to ingested gluten (from wheat, barley, or rye) in genetically susceptible individuals. Coeliac disease has historically been considered to be an uncommon gastrointestinal condition. In addition, most clinicians expect to recognise infant or childhood presentations with overt symptoms of malabsorption (or failure to thrive).

A paradigm shift has occurred, however, in our conceptual understanding of coeliac disease. Recent international studies assessing the prevalence of coeliac disease in the general population have consistently reported that coeliac disease affects $0.5-1 \%$ of all adults. ${ }^{\mathrm{wl}}$ Adult presentations are now more frequent than paediatric (a ratio of 9:1, according to the 2005 membership data of the Coeliac UK charity). Patients most commonly present during their $40 \mathrm{~s}^{\mathrm{w} 2}$

Patients with adult coeliac disease rarely present with symptoms suggestive of malabsorption (low body mass index accounts for $5 \%$ of all cases diagnosed, with most having either a normal or overweight body mass index $\left.{ }^{\mathrm{w} 3}\right)$. Far more commonly they describe nonspecific or subtle gastrointestinal symptoms (for example, non-specific abdominal pain, symptoms similar to those of irritable bowel syndrome, or even upper gastrointestinal symptoms $5^{5}$ ). Any gastrointestinal presentation of coeliac disease is now broadly described as the typical (classic) form. However, a substantial proportion of patients have no gastrointestinal symptoms but present with extraintestinal manifestations (box) and/or recognised associated conditions (table). This manner of presentation is now called the atypical or silent form (figure). Patients who present in this way may initially be overlooked because of the lack of gastrointestinal symptoms. ${ }^{78}$ Finally, some individuals may have the potential to develop coeliac disease (figure).
The increasing recognition of coeliac disease is attributed to several factors: new serological assays; advances in flexible endoscopy, allowing clinicians to take duodenal biopsies easily at the time of gastroscopy; and the realisation that patients often do not have gastrointestinal symptoms.

\section{Diagnosis}

What serological tests should be performed?

Immunoglobulin ( $\mathrm{Ig}$ ) $\mathrm{G}$ and IgA gliadin antibodies lack sensitivity by comparison with IgA endomysial antibody. However, there are limitations to the use of endomysial antibody:

- Oesophagus from the rhesus monkey (an endangered species) or human umbilical cord are still required as a substrate to test for endomysial antibodies in serum

- The test is qualitative, involving subjective interpretation of the immunofluorescence staining

- Endomysial antibody can be negative in patients with lesser degrees of villous atrophy.

The more recent development of IgA tissue transglutaminase antibody has provided the clinician with an alternative to endomysial antibody. Current reports validating tissue transglutaminase antibody in clinical practice give a sensitivity of $91-95 \%$ and a negative

Symptoms in patients presenting with coeliac disease ${ }^{\star}$

\section{Gastrointestinal presenting symptoms}

Abdominal pain

Diarrhoea

Steatorrhoea

Bloating

Non-specific gastrointestinal

Non-gastrointestinal symptoms

Weight loss

Fatigue or "tired all the time"

Arthralgia, arthritis, and myalgia

Skin rash (dermatitis herpetiformis) and aphthous ulcers

Depression or neurological symptoms

*Although these symptoms are common in primary care, we suggest that clinicians should test patients if symptoms are persistent or recurrent, if multiple symptoms are present, or if secondary care referral is being considered 


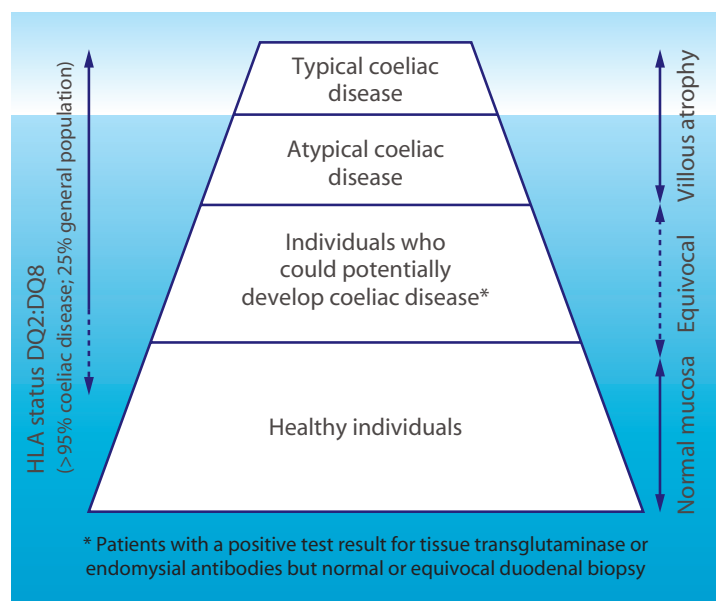

Iceberg model, showing the hidden forms of coeliac disease lying below the waterline

predictive value of near $100 \% \cdot{ }^{910}$ False positive tissue transglutaminase antibody results may occur in chronic liver disease, myeloma, monoclonal gamopathy, and type 1 diabetes. ${ }^{\mathrm{w} 4}$ Tissue transglutaminase antibody has a similar sensitivity and specificity to endomysial antibody but is a quantitative test (enzyme linked immunosorbent assay), which is quicker to perform and cheaper. The positive predictive value of endomysial antibody and tissue transglutaminase antibody together is in excess of $90 \% .^{910}$

Many centres now measure tissue transglutaminase antibody as the first line test and then endomysial antibody in patients who are positive for tissue transglutaminase antibody. This approach is pragmatic and cost effective but has not been adopted universally. Some centres (including our own) still measure endomysial antibody and tissue transglutaminase antibody as a paired serological test to avoid missing cases that are endomysial antibody negative or tissue transglutaminase antibody negative. Both endomysial antibody and tissue transglutaminase antibody may be negative in the presence of IgA deficiency as they are both IgA based tests. Coeliac disease is associated with IgA deficiency, therefore IgA immunoglobulin level should also be requested when investigating a patient for coeliac disease.

What are the pitfalls in duodenal biopsy and what is antibody negative coeliac disease?

In the presence of a positive antibody the patient should be referred to a gastroenterologist for confirmation of the diagnosis by means of duodenal biopsy. Serology has been proposed as a possible replacement for duodenal biopsy, but serological tests have not reached a sufficient standard to recommend this. ${ }^{11}$ It is therefore essential to advise patients to continue eating a normal diet (that is, containing gluten) until a biopsy is performed as withdrawal of gluten may result in an equivocal or normal biopsy result.
Histological demonstration of small bowel villous atrophy remains the optimal method for making the diagnosis of coeliac disease. Seronegative (antibody negative) coeliac disease can occur, even in the presence of a normal serum IgA. The prevalence of seronegative coeliac disease is $6.4-9.1 \%$ of all diagnosed cases. ${ }^{12}$ Therefore a duodenal biopsy should be performed in patients in whom coeliac disease is strongly suspected even if they have a negative coeliac antibody profile. Seronegative coeliac disease may occur in patients who have more severe disease (these individuals are often older). ${ }^{13}$ Conversely, both tissue transglutaminase antibody and endomysial antibody may also be negative in patients with less severe mucosal lesions. ${ }^{\mathrm{w} 5}$ For these cases, confirming the diagnosis with a histological and symptomatic response to a gluten-free diet as well as supportive HLA typing ensures that patients are not incorrectly diagnosed as having coeliac disease.

When considering symptomatic individuals with a family history of coeliac disease (first degree relative), even if the serology is negative a referral to a gastroenterologist for HLA typing (with possible duodenal biopsy) may be warranted. This strategy will ensure that the number of cases missed is minimised. ${ }^{15}$

\section{What are the risks for people with coeliac disease?}

Recent population based studies suggest that patients with coeliac disease have only a modestly increased risk of malignancy and mortality. This risk seems to fall as time from diagnosis increases (in those patients who comply with a gluten-free diet). ${ }^{\text {w6-w8 }}$ Although small bowel lymphoma may be 50 times more common in someone with coeliac disease, the annual incidence is low (0.5-1 per million people), so the absolute risk for patients with coeliac disease is modest.

At the time of diagnosis reduced bone mineral density (osteoporosis or osteopenia) has been shown in 40\% of patients with coeliac disease. ${ }^{\mathrm{w} 9}$ The reduced bone mineral density also translates to an increased risk of fracture ${ }^{16}$ but this risk is modest, with recent studies describing a rate ratio of 1.9 for hip fractures (compared with healthy controls). ${ }^{17}$ Current recommendations suggest that all patients with coeliac disease should have dual energy $x$ ray absorptiometry either at presentation or follow-up. ${ }^{18}$

\section{TIPS FOR NON-SPECIALISTS}

- Case finding for coeliac disease with recognition of a collection of symptoms and associated diseases will increase detection

- Not all patients with coeliac disease experience weight loss or gastrointestinal symptoms

- Patients in whom coeliac disease is suspected should be advised to avoid starting a gluten-free diet until diagnostic confirmation with duodenal biopsy

- Compliance with a gluten-free diet can be improved by specialist long term follow-up 


\section{SOURCES AND SELECTION CRITERIA}

This review is based on key papers found via a search on PubMed and the Cochrane database using keywords "Coeliac disease" and "Gluten sensitivity" (from January 1990 until June 2007), the proceedings of the recent international coeliac symposium (New York, 2006), and published international guidelines.

Infertility, reduced fertility, and an increased risk of an adverse outcome during pregnancy (miscarriage, low birth weight, and intrauterine growth retardation) have all been attributed to undiagnosed coeliac disease. However, these risks may be lower than historically described. ${ }^{\text {w10 }}$

Functional hyposplenism has been shown to occur in $30 \%$ of patients with coeliac disease - for this reason, Haemophilus influenzae, pneumococcal, and annual influenza vaccination should be offered to the patient if there is evidence of hyposplenism on a blood film. ${ }^{19}$

In general, all the potential complications described are either reversible or avoidable by complying with a gluten-free diet. With specific regard to reduced bone mineral density, following a gluten-free diet may either maintain or improve the density. ${ }^{\text {w11 }}$

The initial improvement in quality of life after one year of starting a gluten-free diet may not be sustained at the same level in the long term. However, although patients with coeliac disease may have a poorer quality of life than controls, it is still an improvement compared with their life before diagnosis, particularly for the patients who presented with typical symptoms. ${ }^{\text {w12 }}$

\section{Who should be tested and what are the unresolved controversies?}

Coeliac disease should be considered and tested for when several symptoms and/or disease associations

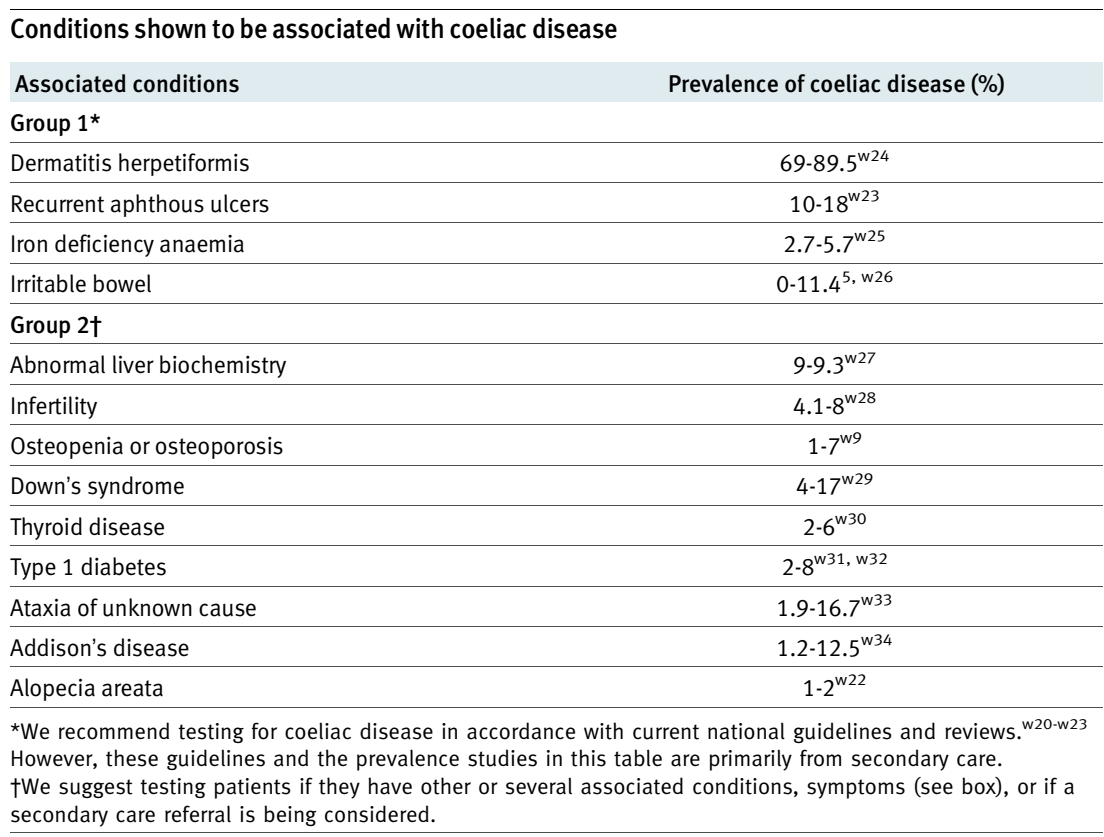

\section{A PATIENT'S PERSPECTIVE}

I'm 43, female, and was diagnosed with coeliac disease in May 2006. I had symptoms for at least five years before changing my diet. These symptoms were bloating, bad stomach cramps, and constipation. I was sent for a gastroscopy at the start of the symptoms and was told I had oesophagitis; antacid tablets didn't work. I have been told I was anaemic from time to time all my life, which wasn't followed up. Eventually I got tested for coeliac disease when I was shown to be anaemic again during investigations for a painful wrist. I had never really heard of coeliac disease until I was diagnosed, and now l'm going to advise two of my sisters who have bowel trouble to have blood tests, from information l've learnt since being diagnosed.

Since changing my diet l'm going to the toilet every day and have no pains. Although I get prescriptions for gluten-free foods, I find supermarket gluten-free foods expensive. I check the Coeliac UK website for new gluten-free products each month. My main problem at the moment is eating out. I currently arrange to meet people for drinks after they have eaten, as twice l've been caught out suffering with stomach cramps soon after eating out myself.

are identified (see box and table). The prevalence of coeliac disease among first degree relatives is reported as $4-22.5 \%,{ }^{\text {w13 }}$ so they too should receive counselling and be offered testing.

Some might argue that coeliac disease fulfils the tenets of any screening programme, but when would we decide to screen? At what age and how often thereafter? Serological markers may be highly sensitive and specific, but the value of these tests decreases when they are used in the general population. Although the investigational process for population screening and case finding may be the same, there is an important ethical difference between them. If a patient seeks medical help, then the physician is trying to diagnose the underlying condition. This would be classified as case finding and clearly it is the patient who has initiated the consultation and in some sense is giving consent for investigation. However, individuals who were not patients but have been found to have coeliac disease through a screening programme may have considered themselves to be "well," and it is the physician or healthcare system that is identifying them as potentially ill. ${ }^{20}$ Despite some evidence showing that overall quality of life is improved in screen detected patients, this benefit seems to be short lived, with subsequent poor compliance with a gluten-free diet. ${ }^{\mathrm{w} 14}$

\section{Management}

Patients who have a positive antibody or in whom coeliac disease is strongly suspected should be referred to a gastroenterologist. A biopsy before starting a gluten-free diet is mandatory. Histological confirmation ensures validity of the diagnosis, allows an assessment of the degree of histological severity as a baseline (should symptoms not improve), and influences any advice about family screening. 


SUMMARY POINTS
The prevalence of coeliac disease is $0.5-1 \%$ in international
population studies
A combination of tissue transglutaminase antibody,
endomysial antibody, and immunoglobulin A should be
used for initial testing
Antibody negative coeliac disease with villous atrophy is
now recognised
Treatment should involve a gluten-free diet, with support
from a dietitian and a gastroenterologist

Confirmation of the diagnosis based on resolution of symptoms with gluten exclusion alone may ultimately result in confusion for the patient. This point can be illustrated in patients with irritable bowel syndrome who have had a normal duodenal biopsy but who may benefit from a gluten-free diet. ${ }^{\mathrm{w} 15}$

A gluten-free diet can be a major and initially overwhelming undertaking. However, it is the cornerstone of treatment in coeliac disease. For this reason, expert dietetic advice is essential. A dietitian's role enables improvement of symptoms and avoidance of nutritional deficiencies related to both the coeliac disease and a subsequent gluten-free diet. The dietitian's role encompasses education about iron, folate, vitamin B-12, fibre, calcium, and vitamin D. ${ }^{21}$ The role increases further when advice is required for the weight gain that can occur when the small bowel recovers. Compliance with a gluten-free diet may be compromised by a lack of education, limited medical support (from doctors and dietitians), or the absence of symptoms at the time of diagnosis (or in screen detected patients). ${ }^{22}$ Compliance can be assessed by repeating the duodenal biopsy, antibody testing (levels should normalise on a gluten-free diet), dietary history, and symptom resolution.

Patients are recommended to have a yearly followup with a dietitian or doctor to help compliance, as the best evidence to date is that regular specialist follow-up

\section{ADDITIONAL EDUCATIONAL RESOURCES}

\section{Resources for healthcare professionals}

- British Society of Gastroenterology. Interim guidelines for the management of patients with coeliac disease. 2002. (www.bsg.org.uk)

- Clinical Resource Efficiency Support Team (Northern Ireland). Guidelines for the diagnosis and management of coeliac disease in adults. 2006. (www.crestni.org.uk/ publications-show?txtid=4025)

- Primary Care Society for Gastroenterology. Follow-up care of adult coeliac disease. 2001 (www.pcsg.org.uk/downloads/PCSGCoeliacFollowUp2001.pdf)

Resources for patients

- Coeliac UK (www.coeliac.co.uk)—A charity working for people with coeliac disease. Tel 01494437 278; or helpline 08704448804 (to speak to a Coeliac UK dietitian or ask about a gluten-free products).

- Celiac Disease Foundation (www.celiac.org)—Provides support and information to people affected by coeliac disease. Tel (00) 18189902354.

- Gluten Intolerance Group (a US non-profit organisation). Quick start diet guide for celiac disease. 2005. (www.gluten.net/downloads/print/QuickStartDietGuide-2005. pdf)

\section{ONGOING RESEARCH}

- Finger prick testing for IgA tissue transglutaminase antibody could become readily available at point of care

- Supplements to enable digestion of gluten before its entry into the small bowel could make it possible for coeliac patients to follow a normal diet

- Easy detection of gliadins in foods would enable better food safety for patients

Unanswered clinical research questions

- The natural course of screening detected coeliac disease is unknown

- Does case finding in certain diseases associated with coeliac disease improve the patient's quality of life?

improves compliance. ${ }^{23}$ Patient surveys show that the optimal follow-up is an appointment with a dietitian in a dedicated clinic but with specialist medical expertise available (concurrently) should they require it. ${ }^{\text {w16 }}$ Reasons for lapses in a gluten-free diet include poor palatability, the absence of a recurrence of symptoms after lapses, high cost of gluten-free products, and the unspecified presence of gluten in food and medications. ${ }^{24}$ Patients who are established on a gluten-free diet may be able to reintroduce oats. Oats have been shown to be safe in several long term studies, ${ }^{\text {w17 }}$ although cross contamination with wheat flour has been shown (and occasionally "molecular mimicry"), which may result in a recurrence of symptoms. ${ }^{\text {w17 w18 }}$

If symptoms persist despite a gluten-free diet, the most common reason is inadvertent non-compliance. However, several other conditions are linked to coeliac disease and can cause persisting symptoms, so a gastroenterological opinion should be sought. ${ }^{\text {w19 }}$

\section{Conclusion}

Many alternatives to a gluten-free diet are being evaluated (see "Ongoing research" box). However, an important aspect of the new therapies is that they could have as yet unreported side effects or complications, whereas a gluten-free diet is safe. ${ }^{25}$

In conclusion, adult coeliac disease is common with many undetected cases still present in the community. We and others have shown a delay in diagnosis in patients with coeliac disease-perhaps the important change in our clinical practice (both in primary and secondary care) is to have a low threshold for case finding and serological testing.

Contributors: $\mathrm{ADH}$ designed and drafted the article and is the guarantor. $\mathrm{MH}$ and SB revised the article and approved the final manuscript. DSS designed and revised the article and approved the final manuscript.

Competing interests: DSS is an associate medical adviser for the charity Coeliac UK and is chairman of the small bowel and nutrition committee of the British Society of Gastroenterology; SB is on the medical advisory council for Coeliac UK. These are honorary posts with no financial benefits. SB has also received reimbursement for attending symposiums and fees for consulting from SHS (makers of gluten-free food).

Provenance and peer review: Commissioned and externally peer reviewed. 
1 Lo W, Sano K, Lebwohl B, Diamond B, Green PH. Changing presentation of adult celiac disease. Dig Dis Sci 2003;48:395-8.

2 Sanders DS, Hurlstone DP, Stokes RO, Rashid F, Milford-Ward A, Hadjivassiliou M, et al. Changing face of adult coeliac disease: experience of a single university hospital in south Yorkshire. Postgrad Med I 2002;78(915):31-3.

3 Dickey W, McConnell JB. How many hospital visits does it take before celiac sprue is diagnosed? J Clin Gastroenterol 1996;23(1):21-3.

4 Van Heel DA, West J. Recent advances in coeliac disease. Gut 2006;55:1037-46.

5 Sanders DS, Carter MJ, Hurlstone DP, Pearce A, Ward AM, McAlindon ME, et al. Association of adult coeliac disease with irritable bowel syndrome: a case-control study in patients fulfilling ROME II criteria referred to secondary care. Lancet 2001;358:1504-8.

6 Sanders DS, Hopper AD, Azmy IA, Rahman N, Hurlstone DP, Leeds JS, et al. Association of adult celiac disease with surgical abdominal pain: a case-control study in patients referred to secondary care. Ann Surg 2005;242:201-7.

7 Fasano A. Celiac disease-how to handle a clinical chameleon. N Engl J Med 2003;348:2568-70.

8 Ferguson A, Arranz E, O'Mahony S. Clinical and pathological spectrum of coeliac disease-active, silent, latent, potential. Gut 1993;34:150-1.

9 Hopper AD, Cross SS, Hurlstone DP, McAlindon ME, Lobo AJ, Hadjivassiliou M, et al. Pre-endoscopy serological testing for coeliac disease: evaluation of a clinical decision tool. BMJ 2007;334:729-32.

10 Lewis BS, Swain P. Capsule endoscopy in the evaluation of patients with suspected small intestinal bleeding: results of a pilot study. Gastrointest Endosc 2002;56:349-53.

11 Scoglio R, Di Pasquale G, Pagano G, Lucanto MC, Magazzù G, Sferlazzas C. Is intestinal biopsy always needed for diagnosis of celiac disease? Am J Gastroenterol 2003;98:1325-31.

12 Collin P, Kaukinen K, Vogelsang H, Korponay-Szabo I, Sommer R, Schreier E, et al. Antiendomysial and antihuman recombinant tissue transglutaminase antibodies in the diagnosis of coeliac disease: a biopsy-proven European multicentre study. Eur J Gastroenterol Hepatol 2005;17(1):85-91.

13 Salmi TT, Collin P, Korponay-Szabo IR, Laurila K, Partanen J, Huhtala $\mathrm{H}$, et al. Endomysial antibody-negative coeliac disease: clinical characteristics and intestinal autoantibody deposits. Gut 2006;55:1746-53.

14 Sanders DS, Hurlstone DP, McAlindon ME, Hadjivassiliou M, Cross SS, Wild G, et al. Antibody negative coeliac disease presenting in elderly people-an easily missed diagnosis. BMJ 2005;330:775-6.

15 Esteve M, Rosinach M, Fernandez-Banares F, Farre C, Salas A, Alsina $M$, et al. Spectrum of gluten-sensitive enteropathy in firstdegree relatives of patients with coeliac disease: clinical relevance of lymphocytic enteritis. Gut 2006;55:1739-45.

16 Walters JR. Analysis of the absolute risks in coeliac disease indicates the importance of the prevention of osteoporosis. Gut 2007;56:310. (Author reply, pp 310-1.)

17 West J, Logan RF, Card TR, Smith C, Hubbard R. Fracture risk in people with celiac disease: a population-based cohort study. Gastroenterology 2003;125:429-36.

18 American Gastroenterological Association. Medical position statement: celiac sprue. Gastroenterology 2001;120:1522-5

19 Corazza GR, Zoli G, Di Sabatino A, Ciccocioppo R, Gasbarrini G. A reassessment of splenic hypofunction in celiac disease. Am J Gastroenterol 1999;94:391-7.

20 Sanders DS. Coeliac disease: is case finding the correct ethical and logistical approach? Gut 2003;52:1070-1. (Author reply, p 1071.)

21 Thompson T, Dennis M, Higgins LA, Lee AR, Sharrett MK. Gluten-free diet survey: are Americans with coeliac disease consuming recommended amounts of fibre, iron, calcium and grain foods? I Hum Nutr Diet 2005;18:163-9.

22 Ciacci C, Cirillo M, Cavallaro R, Mazzacca G. Long-term follow-up of celiac adults on gluten-free diet: prevalence and correlates of intestinal damage. Digestion 2002;66:178-85.

23 Bardella MT, Molteni N, Prampolini L, Giunta AM, Baldassarri AR, Morganti D, et al. Need for follow up in coeliac disease. Arch Dis Child 1994;70:211-3.

24 Vahedi K, Mascart F, Mary JY, Laberenne JE, Bouhnik Y, Morin MC et al. Reliability of antitransglutaminase antibodies as predictors of gluten-free diet compliance in adult celiac disease. Am J Gastroenterol 2003;98:1079-87.

25 Elli L. Coeliac disease: between "pizza" and ethics. Gut 2006;55:1672.

\section{Trust me}

In recent months, much has been written about the UK government's efforts to undermine doctors, to reduce us from autonomous professionals to tick-box automatons. With the forced implementation of the Medical Training Application Service (MTAS), the government has begun to succeed. But there are some things that it cannot eradicate, much as it would love to.

Five years ago June and her husband were both diagnosed with cancer within a year of each other. They both underwent treatment, and June has just been given her five year clean bill of health. Her husband was not so lucky. Three years ago last weekend he died, a few days short of their 40th wedding anniversary. June has been heartbroken ever since, but has marched on through life and copes well. She lost all her faith in the medical profession the day her husband lost his battle and blames his doctors for her loss.

In July the erratic weather conditions caused flash floods in the village, and June was trapped in her home by rising water levels. My neighbour asked me for my help, as June was refusing to leave her home, and all her memories of her husband. "You're a doctor," my neighbour said, "you'll know what to do." Unconvinced, I agreed to go and see June and try to persuade her out of her house to stay with her family until the water levels dropped.

After wading through waist-deep water, with all manner of flotsam and jetsam flowing around us, we reached June's back door and paddled in. June was upstairs, and my neighbour, who knows June well, introduced me by name. I had a long conversation with June about the necessity of her going somewhere warm and dry, to return when it was safe to do so. But she was distraught and would not listen to reason. I cajoled and pleaded, occasionally thinking I was making some headway, but it always came down to her refusal to leave all her husband's things behind-her reminders of her previous happiness.

I was beginning to despair of ever helping June to safety and was clutching at any persuasive argument I could summon, but to no avail. It was getting increasingly dark and cold, and June was starting to shiver from being in her wet clothes too long. And then I heard myself say it: "Trust me, June, I'm a doctor." Quietly she nodded and started packing an overnight bag. My neighbour and I helped her to safety through the flood, and when she was dry and warm, with a mug of hot sweet tea and a stiff gin and tonic inside her, she went to her daughter's home willingly.

June is an ordinary person with an ordinary experience of ill health and loss. But she gained extraordinary strength from the fact that I was a doctor, and she trusted me. That makes it all worth while. And whatever the government does to my career in the coming months and years, it can't take that away from me.

Competing interests: I have been unsuccessful in the recent MTAS lottery and am grasping at anything resembling hope or goodwill.

Elizabeth M McEvoy clinical lecturer in medical education, Warwick Medical School, University of Warwick, Coventry lizkerfordbyrnes@doctors.org.uk 